\title{
A new species of the genus Rana sensu lato Linnaeus, 1758 (Anura, Ranidae) from Wuyi Mountain, Fujian Province, China
}

\author{
Yanqing Wu ${ }^{{ }^{*}}$, Shengchao Shi ${ }^{*}$, Huiguang Zhang ${ }^{3}$, Weicai Chen ${ }^{4}$, \\ Bin $\mathrm{Cai}^{3}$, Van Chung Hoang ${ }^{2,5}$, Jun Wu', Bin Wang ${ }^{2}$
}

I Nanjing Institute of Environmental Sciences, Ministry of Ecology and Environment of China, Nanjing 210042, China 2 Chengdu Institute of Biology, Chinese Academy of Sciences, Chengdu 610041, China 3 Research and Monitoring Center, Wuyishan National Park, Wuyishan 354300, China 4 Key Laboratory of Beibu Gulf Environment Change and Resources Utilization of Ministry of Education, Nanning Normal University, Nanning 530001, China 5 Forest Resources and Environment Center, 300 Ngoc Hoi Road, Thanh Tri, Hanoi, Vietnam

Corresponding authors: Jun Wu (wujun@nies.org); Bin Wang (wangbin@cib.ac.cn)

Academic editor: Annemarie Ohler | Received 6 April 2021 | Accepted 1 September 2021 | Published 26 October 2021

http://zoobank.org/B991C304-8F01-406E-BB39-ED1993601125

Citation: Wu Y, Shi S, Zhang H, Chen W, Cai B, Hoang VC, Wu J, Wang B (2021) A new species of the genus Rana sensu lato Linnaeus, 1758 (Anura, Ranidae) from Wuyi Mountain, Fujian Province, China. ZooKeys 1065: 101-124. https://doi.org/10.3897/zookeys.1065.67005

\begin{abstract}
A new species of the frog genus Rana sensu lato from Wuyi Mountain, Fujian Province, China is described. Molecular phylogenetic analyses clustered the new species into the $R$. johnsi group and indicated that it was genetically divergent from its closely related species. The new species could be distinguished from its congeners by a combination of the following characters: body size medium, SVL 41.4-45.6 mm $(42.9 \pm 1.9 \mathrm{~mm}, \mathrm{n}=4)$ in adult males and $47.6-50.3 \mathrm{~mm}(\mathrm{n}=2)$ in adult females; adult male with a pair of internal subgular vocal sacs; lateroventral grooves present on tip of toes; webbing on fourth toes reaching the tip of toe; transverse skin ridges distinctly present on the dorsal surface of thigh and tibia, the number large (mean $26.5 \pm 2.7$, range $22-29, \mathrm{n}=6$ ); breeding males possess creamy white nuptial pad with tiny velvety spines on the dorsal surface of the first finger, divided into three parts.
\end{abstract}

\section{Keywords}

Molecular phylogenetic analyses, morphology, Rana, taxonomy

* These authors have contributed equally to this work.

Copyright Yanqing Wu et al. This is an open access article distributed under the terms of the Creative Commons Attribution License (CC BY 4.0), which permits unrestricted use, distribution, and reproduction in any medium, provided the original author and source are credited. 


\section{Introduction}

The brown frog genus Rana sensu lato Linnaeus, 1758 (Anura, Ranidae Batsch, 1796) is broadly distributed across Eurasia, Indochina, and North America (Frost 2021). The taxonomic arrangements in the group have been controversial for a long time (e.g., Fei et al. 1990; Dubois 1992; Fei et al. 2005, 2009, 2010, 2012; Frost et al. 2006; Che et al. 2007; Pyron and Wiens 2011; Jiang et al. 2020; Wang et al. 2020). A recent phylogenetic framework (Yuan et al. 2016) indicated that Rana sensu lato contained nine clades corresponding to eight subgenera and one unresolved species, i.e., Rana, Amerana Dubois, 1992, Liuhurana Fei, Ye, Jiang, Dubois \& Ohler, 2010, Aquarana Dubois, 1992, Lithobates Fitzinger, 1843, Zweifelia Dubois, 1992, Pantherana Dubois, 1992, Pseudorana Fei, Ye \& Huang, 1990, and R. sylvatica LeConte, 1825. Dubois et al. (2021) upgraded these subgenera to genera (except that the members of Zweifelia were placed in Lithobates) within Ranites Batsch, 1796, and established the new genus Boreorana Dubois, Ohler \& Pryon, 2021 based on the type species Rana sylvatica. In the genus Rana sensu lato, 26 species have been recorded in China (Jiang et al. 2020; Wang et al. 2020; Frost 2021), which are $R$. amurensis Boulenger, 1886, $R$. arvalis Nilsson, 1842 , $R$. asiatica Bedriaga, 1898, $R$. chaochiaoensis Liu, 1946, R. chensinensis David, $1875, R$. chevronta Hu \& Ye, 1978, R. coreana Okada, 1928, R. culaiensis Li, Lu, \& Li, 2008, R. dabieshanensis Wang, Qian, Zhang, Guo, Pan, Wu, Wang, \& Zhang, 2017, R. dybowskii Günther, 1876, R. hanluica Shen, Jiang, \& Yang, 2007, R. huanrenensis Fei, Ye, \& Huang, 1990, R. jiemuxiensis Yan, Jiang, Chen, Fang, Jin, Li, Wang, Murphy, Che, \& Zhang, 2011, R. jiulingensis Wan, Lyu, \& Wang, 2020, R. johnsi Smith, 1921, $R$. kukunoris Nikolskii, 1918, R. longicrus Stejneger, 1898, R. luanchuanensis Zhao \& Yuan, 2017, $R$. maoershanensis Lu, Li, \& Jiang, 2007, $R$. omeimontis Ye \& Fei, 1993, $R$. sangzhiensis Shen, 1986, $R$. sauteri Boulenger, 1909, $R$. shuchinae Liu, 1950, $R$. weiningensis Liu, Hu, \& Yang, 1962, R. zhengi Zhao, 1999, and $R$. zhenhaiensis Ye, Fei, \& Matsui, 1995. Recent research on this genus discovered several new species from China (Yan et al. 2011; Yuan et al. 2016; Wang et al. 2017; Yang et al. 2017; Zhao et al. 2017), indicating that the diversity of the genus is probably underestimated.

Recently, in Wuyishan National Park, Wuyishan City, Fujian Province, China, we collected several specimens which can be assigned to Rana sensu lato based on morphology. Molecular phylogenetic analyses and detailed morphological comparisons indicated the specimens represented an undescribed species of the $R$. johnsi group. Herein we described it as a new species.

\section{Materials and methods}

\section{Specimens}

Twelve unnamed specimens including four adult males, two adult females, and six tadpoles were collected from Wuyishan National Park, Fujian Province, China (Table 1, Fig. 1, Suppl. material 1). For comparisons, 39 specimens of the subgenus Rana were 


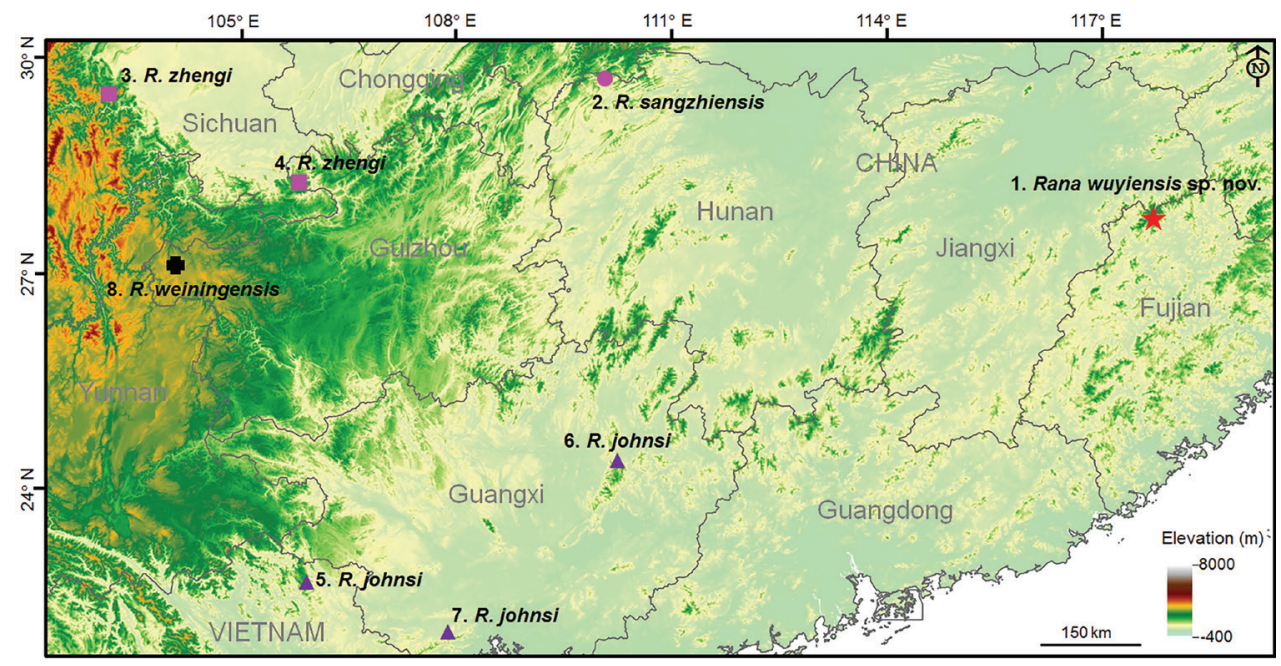

Figure I. Locations for specimens used in this study. 1. the type locality of Rana wuyiensis sp. nov., Wuyi Mountain, Fujian Province, China; 2. the type locality of $R$. sangzhiensis, Sangzhi County, Hunan Province, China; 3. the type locality of $R$. zhengi, Hongya County, Sichuan Province, China; 4. another locality of $R$. zhengi, Gulin County, Sichuan Province, China; 5. the locality for $R$. johnsi in Caobang Province, Vietnam; 6. the locality for $R$. johnsi in Jinxiu County, Guangxi Province, China; 7. the locality for R. johnsi in Shiwandashan Mountains, Guangxi Province, China; 8. the type locality of $R$. weiningensis, Weining County, Guizhou Province, China.

collected, i.e., six $R$. zhengi from Gulin County, Sichuan Province, China; five adult males, two adult females and six tadpoles of $R$. sangzhiensis from its type locality, Sangzhi County, Hunan Province, China; two adult males, one female, and one larval of $R$. johnsi from northern Vietnam; two larval of $R$. johnsi from Jinxiu County, Guangxi Province, China; eight adult males and six tadpoles of $R$. johnsi from Shiwandashan Mountains, Guangxi Province, China; and one adult male of $R$. weiningensis from its type locality, Weining City, Guizhou Province, China (Table 1, Fig. 1, Suppl. material 1). In the field, the frogs and tadpoles were euthanized using isoflurane, and the specimens were fixed in $75 \%$ ethanol. Muscle tissue samples were taken and preserved separately in $95 \%$ ethanol prior to fixation. The specimens were deposited in Chengdu Institute of Biology (CIB), Chinese Academy of Sciences, Nanning Normal University (NNU), and Institute of Ecology and Biological Resources (IEBR), Vietnam (for voucher numbers see Table 1 and Suppl. material 1).

\section{Molecular phylogenetic analyses}

A total of 40 samples collected in this study was used in molecular analyses, encompassing twelve unnamed specimens from Wuyi Mountain, six $R$. sangzhiensis, six $R$. zhengi, $15 R$. johnsi, and one $R$. weiningensis (Table 1). Total DNA was extracted using a standard phenol-chloroform extraction protocol (Sambrook et al. 1989). Three mitochondrial genes (16S rRNA, ND2, and Cyt $b$ ) and three nuclear DNA markers 


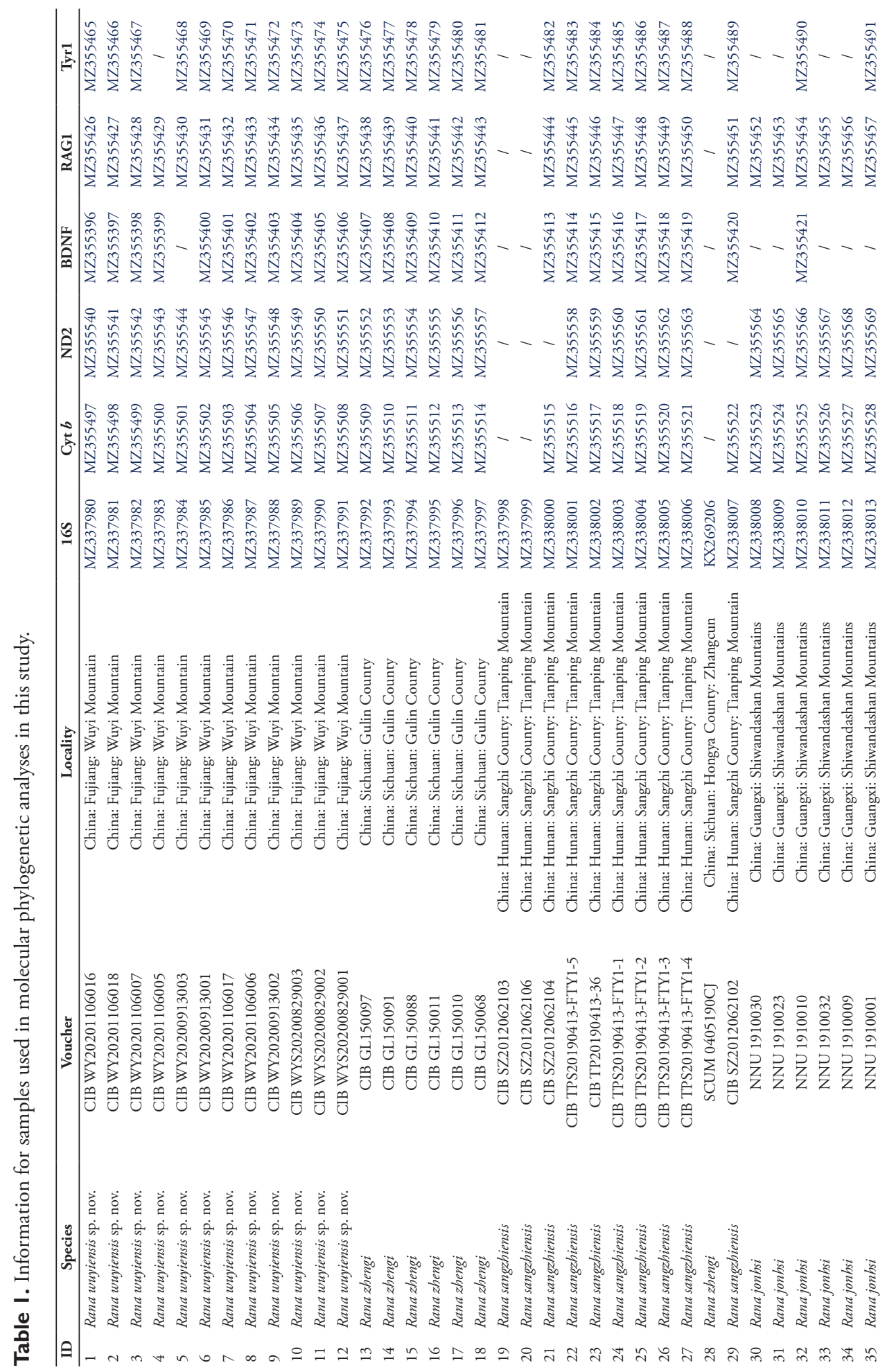




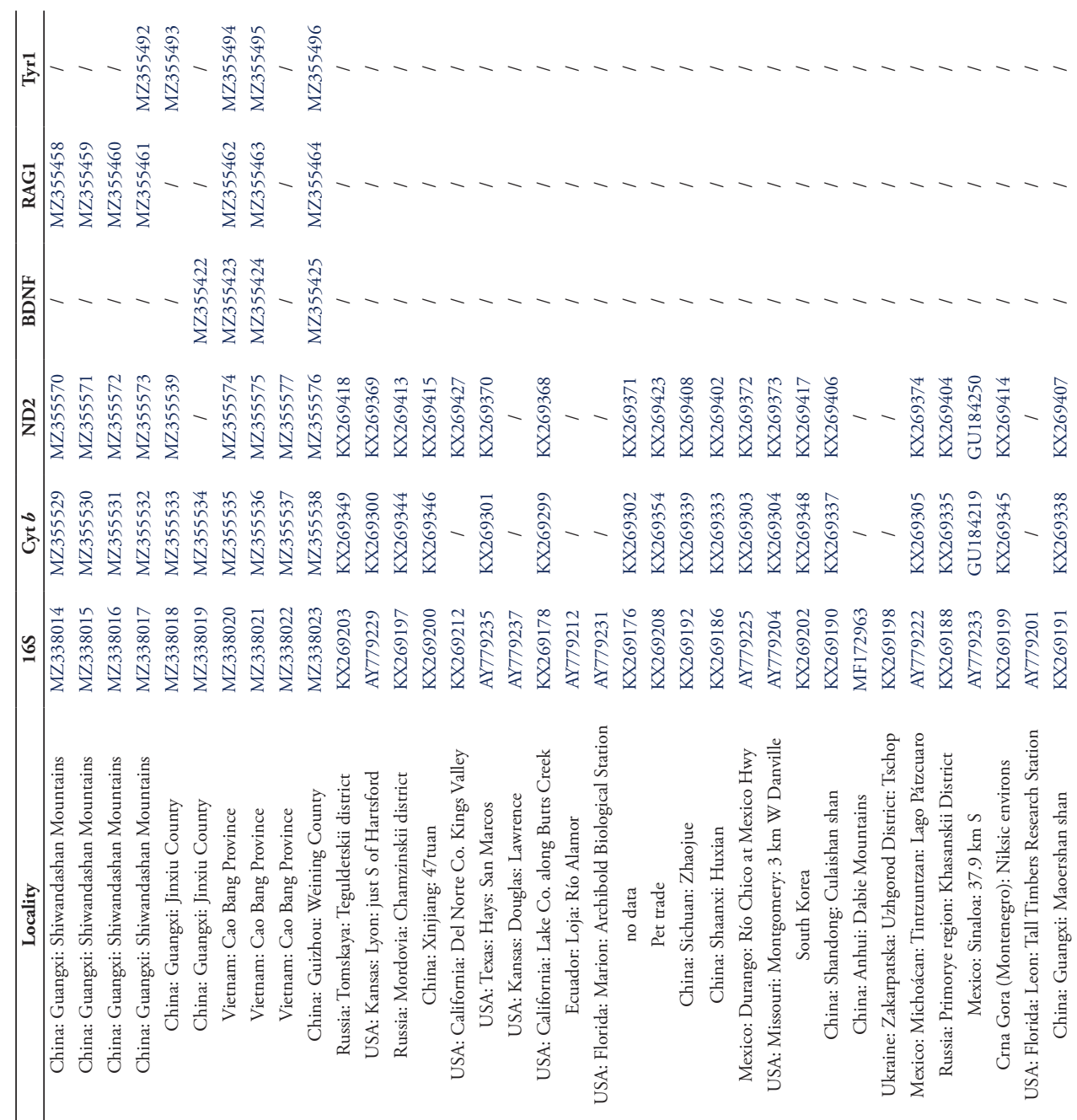

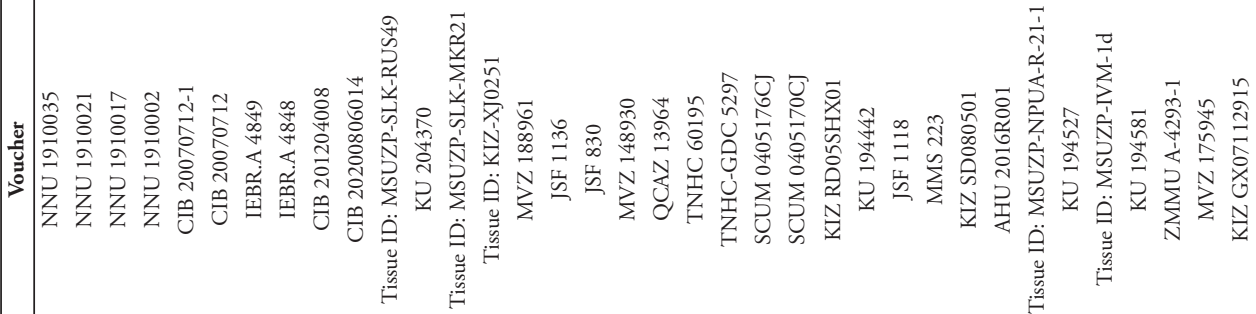

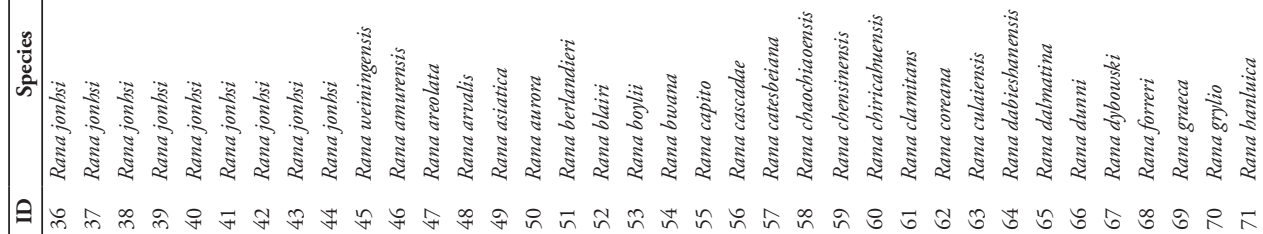




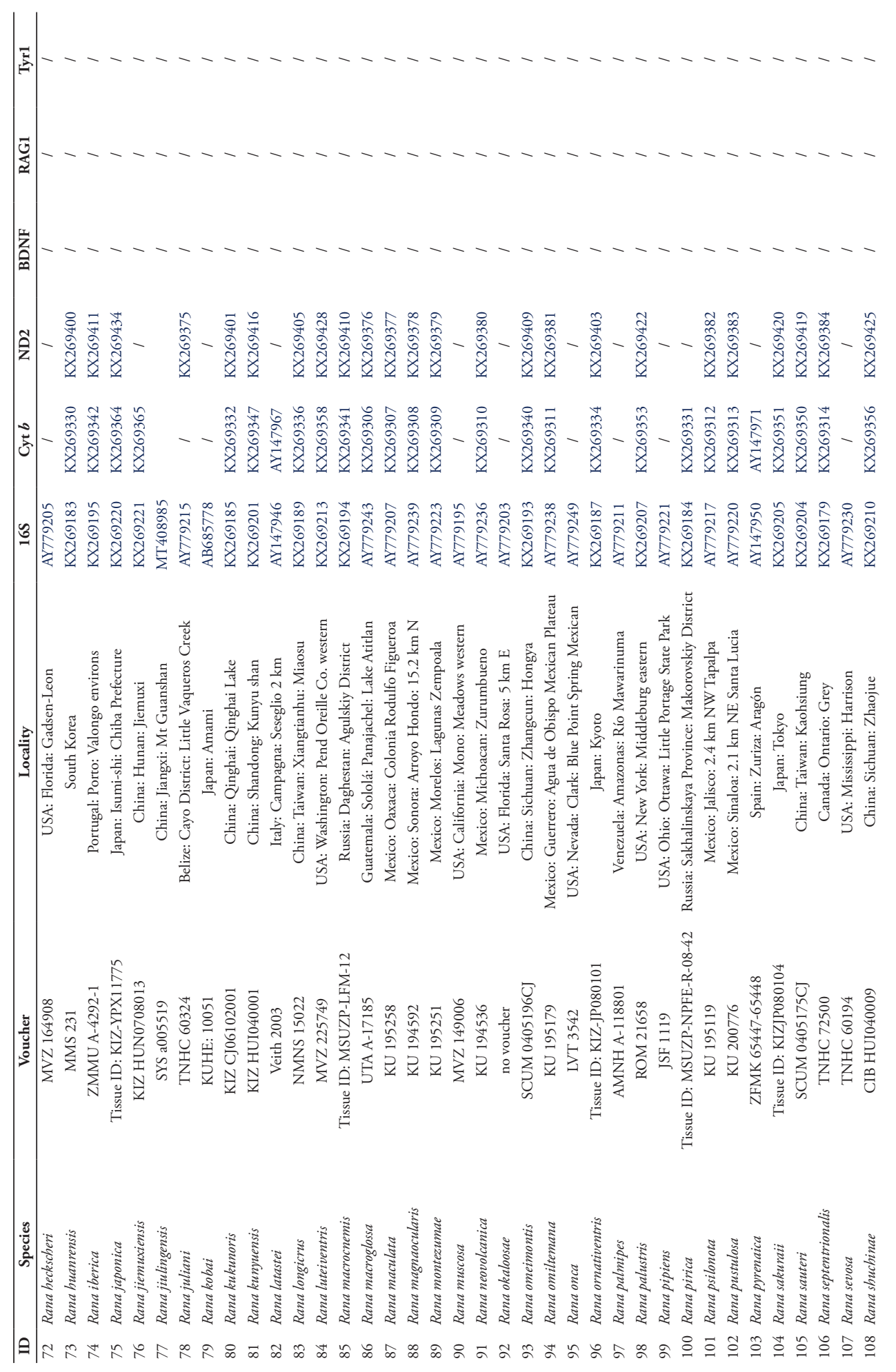



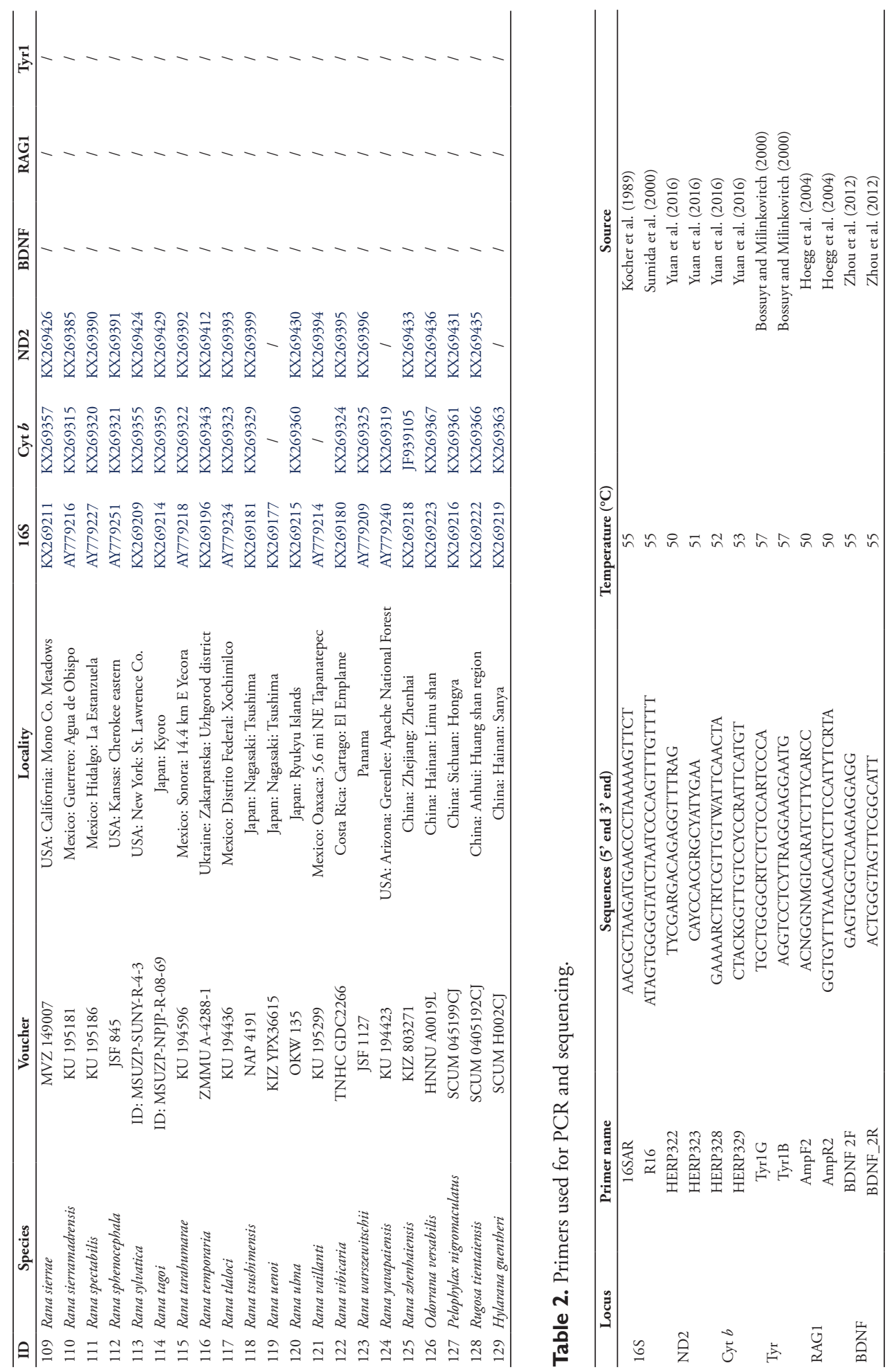
(Tyr, BDNF, and RAG1) were amplified and sequenced for the samples. Primer sequences used for PCR are presented in Table 2. Gene fragments were amplified under the following conditions: an initial denaturing step at $95^{\circ} \mathrm{C}$ for $4 \mathrm{~min} ; 36$ cycles of denaturing at $95^{\circ} \mathrm{C}$ for $30 \mathrm{~s}, 40 \mathrm{~s}$ at appropriate annealing temperature (Table 2); and extending at $72{ }^{\circ} \mathrm{C}$ for $70 \mathrm{~s}$. PCR products were sequenced with primers same as used in PCR. Sequencing was conducted using an ABI3730 automated DNA sequencer. New sequences were deposited in GenBank (Table 1).

For phylogenetic analyses, the corresponding sequences for congeners especially for the topotypes of species in the subgenus Rana were downloaded from GenBank (Table 1), mainly derived from previous studies (Yuan et al. 2016; Wang et al. 2017; Wan et al. 2020). For phylogenetic analyses, corresponding sequences of one Odorrana versabilis (Liu \& Hu, 1962) and one Pelophylax nigromaculatus (Hallowell, 1861) were also downloaded (Table 1), and used as outgroups according to Yuan et al. (2016).

Sequences were assembled and aligned using the ClustalW module in BioEdit v.7.0.9.0 (Hall 1999) with default settings. The protein-coding gene (Cytb, ND2, BDNF, RAG1, and Tyr 1) sequences were translated to amino acid sequences in MEGA v. 6.0 (Tamura et al. 2013), adjusted for open reading frames, and checked to ensure absence of premature stop codons. No-sequenced fragments were treated as missing data. For phylogenetic analyses based on mitochondrial DNA, the dataset was concatenated with mitochondrial gene sequences. The best partition scheme and the best evolutionary model for each partition were chosen for the phylogenetic analyses using PARTITIONFINDER v. 1.1.1 (Robert et al. 2012). In this analysis, 16S gene and each codon position of protein-coding mitochondrial gene were defined, and Bayesian Inference Criteria was used. As a result, the analysis suggested that the best partition scheme is $16 \mathrm{~S}$ gene/ each codon position of protein-coding gene, and selected GTR + G + I model as the best model for each partition. Phylogenetic analyses were conducted using maximum likelihood (ML) and Bayesian Inference (BI) methods, implemented in PhyML v. 3.0 (Guindon et al. 2010) and MrBayes v. 3.2 (Ronquist et al. 2012), respectively. For the ML tree, branch supports (bs) were drawn from 10,000 nonparametric bootstrap replicates. In BI, two runs each with four Markov chains were simultaneously run for 50 million generations with sampling every 1,000 generations. The first $25 \%$ trees were removed as the "burn-in" stage followed by calculations of Bayesian posterior probabilities (bpp), and the $50 \%$ majority-rule consensus of the post burn-in trees were sampled at stationarity. In addition, to access the genetic isolation between the undescribed species and its closely related species on nuclear DNA, one haplotype network for each nuclear gene dataset was constructed, using the maximum parsimony method in TCS v. 1.21 (Clement et al. 2000). Genetic distance of uncorrected-p-distance model on $16 S$ gene sequences between the new species and its closely related species were estimated using MEGA.

\section{Morphological comparisons}

All six adult specimens of the undescribed species were measured (Suppl. material 1). For comparisons, five adult male specimens of $R$. sangzhiensis, eleven adult male 
specimens of $R$. johnsi, and 22 adult male specimens of $R$. zhengi used in Jiang et al. (1997) were also measured (Suppl. material 1). The terminology and methods followed Fei et al. (2009). Measurements were taken with a dial caliper to $0.1 \mathrm{~mm}$. Twenty-two morphometric characters of adult specimens were measured:

ED eye diameter (distance from the anterior corner to the posterior corner of the eye);

FIIIL third finger length (distance from base to tip of finger III);

FIIL second finger length (distance from base to tip of finger II);

FIL first finger length (distance from base to tip of finger I);

FIVL fourth finger length (distance from base to tip of finger IV);

FL foot length (distance from tarsus to the tip of fourth toe);

HAL hand length (distance from tip of third digit to proximal edge of inner palmar tubercle);

HDL head length (distance from the tip of the snout to the articulation of jaw);

HDW maximum head width (greatest width between the left and right articulations of jaw);

IND internasal distance (minimum distance between the inner margins of the external nares);

IOD interorbital distance (minimum distance between the inner edges of the upper eyelids);

LAL length of lower arm and hand (distance from the elbow to the distal end of the Finger IV);

LW lower arm width (maximum width of the lower arm);

SL snout length (distance from the tip of the snout to the anterior corner of the eye);

SNT distance between the nasal the posterior edge of the vent;

SVL snout-vent length (distance from the tip of the snout to the posterior edge of the vent);

TFL length of foot and tarsus (distance from the tibiotarsal articulation to the distal end of the Toe IV);

THL thigh length (distance from vent to knee);

TL tibia length (distance from knee to tarsus);

TW maximal tibia width;

TYD maximal tympanum diameter;

UEW upper eyelid width (greatest width of the upper eyelid margins measured perpendicular to the anterior-posterior axis).

To reduce the impact of allometry in adults, the correct value from the ratio of each character to SVL was calculated, and then was log-transformed for the following morphometric analyses. One-way ANOVA tests were conducted to test the significance of differences on morphometric characters between the undescribed species and its closely related species. The significance level was set at 0.05 .

The morphological description follows the definition in Fei et al. (2009). Sex was determined by examining the gonads. The description of toe webbing followed Savage 
(1975). The description of digital pad followed Ohler (1995). Comparison characters of known congeners were obtained from the literature (Stejneger 1898; Liu 1946; Fei et al. 1990, 2005, 2009, 2012; Liu et al. 1993; Ye et al. 1993, 1995; Lu et al. 2007; Shen et al. 2007; Li et al. 2008; Yan et al. 2011; Wang et al. 2017; Zhao et al. 2017; Wan et al. 2020). We also examined a series of specimens of Rana (Suppl. material 1).

\section{Results}

\section{Phylogenetic analyses}

$\mathrm{ML}$ and $\mathrm{BI}$ trees of the mitochondrial DNA dataset presented almost consistent topology (Fig. 2A, B). In mitochondrial DNA trees, all samples of the undescribed species were strongly nested into one clade (all supports $=100$; Fig. 2B). The $R$. johnsi group was strongly supported as a monophyletic group containing all samples of $R$. johnsi, $R$. sangzhiensis, $R$. zhengi, and the undescribed species (all supports = 100; Fig. 2B). The $R$. johnsi group was clustered into the clade corresponding to the subgenus Rana (Fig. 2A). The $R$. johnsi group contained two clades. In the first clade, samples of $R$. sangzhiensis and $R$. zhengi were nested into a clade (all supports $=100$ ), which was weakly clustered as the sister of the undescribed species clade $(\mathrm{bs}=52$; bpp $=0.80$; Fig. 2B). In the second clade, three $R$. johnsi samples from Vietnam were clustered into one clade, which was sister to the clade containing samples of $R$. johnsi from two localities of Guangxi Province, China (Figs 1, 2B; Table 1). In addition, the topotype specimen of $R$. weiningensis was phylogenetically far from the $R$. johnsi group, and clustered as the basal clade of the genus Rana (Fig. 2A). Haplotype networks based on three nuclear genes all indicated that the undescribed species did not share haplotype with its closely related species $R$. johnsi, $R$. sangzhiensis, and $R$. zhengi (Fig. 2C-E), further indicating the genetic divergence between the undescribed species and its closely related species. As note, on each gene, samples of $R$. sangzhiensis and $R$. zhengi massively shared common haplotypes (Fig. 2C-E), indicating their very shallow genetic divergence. The genetic distance on $16 \mathrm{~S}$ between all samples of undescribed species is less than $0.2 \%$ (range $0.0 \%-0.2 \%)$. The genetic distance between the species and its closely related species were as following: vs. $R$. johnsi from Vietnam $1.3 \%$ (range $1.1 \%-1.7 \%$ ), vs. $R$. johnsi from Guangxi, China $0.8 \%$ (range $0.8 \%-0.9 \%$ ), vs. $R$. zhengi $1.0 \%$ (range $0.9 \%-1.1 \%$ ), and vs. $R$. sangzhiensis $0.9 \%$ (range $0.8 \%-1.1 \%$ ), being similar to that between the latter four groups (range $0.8 \%-1.4 \%$ ). As note, the genetic distance between $R$. zhengi and $R$. sangzhiensis was $0.2 \%$ (range $0.0 \%-0.4 \%$ ), and that between $R$. johnsi from Vietnam and $R$. johnsi from Guangxi, China was $0.5 \%$ (range $0.4 \%-1.1 \%$ ).

\section{Morphological comparisons}

The $R$. johnsi group is phylogenetically clustered into the subgenus Rana, but this group could be identified from other species of the subgenus Rana by the tip of toes with lateroventral grooves (vs. absent in other species of subgenus Rana). The undescribed 


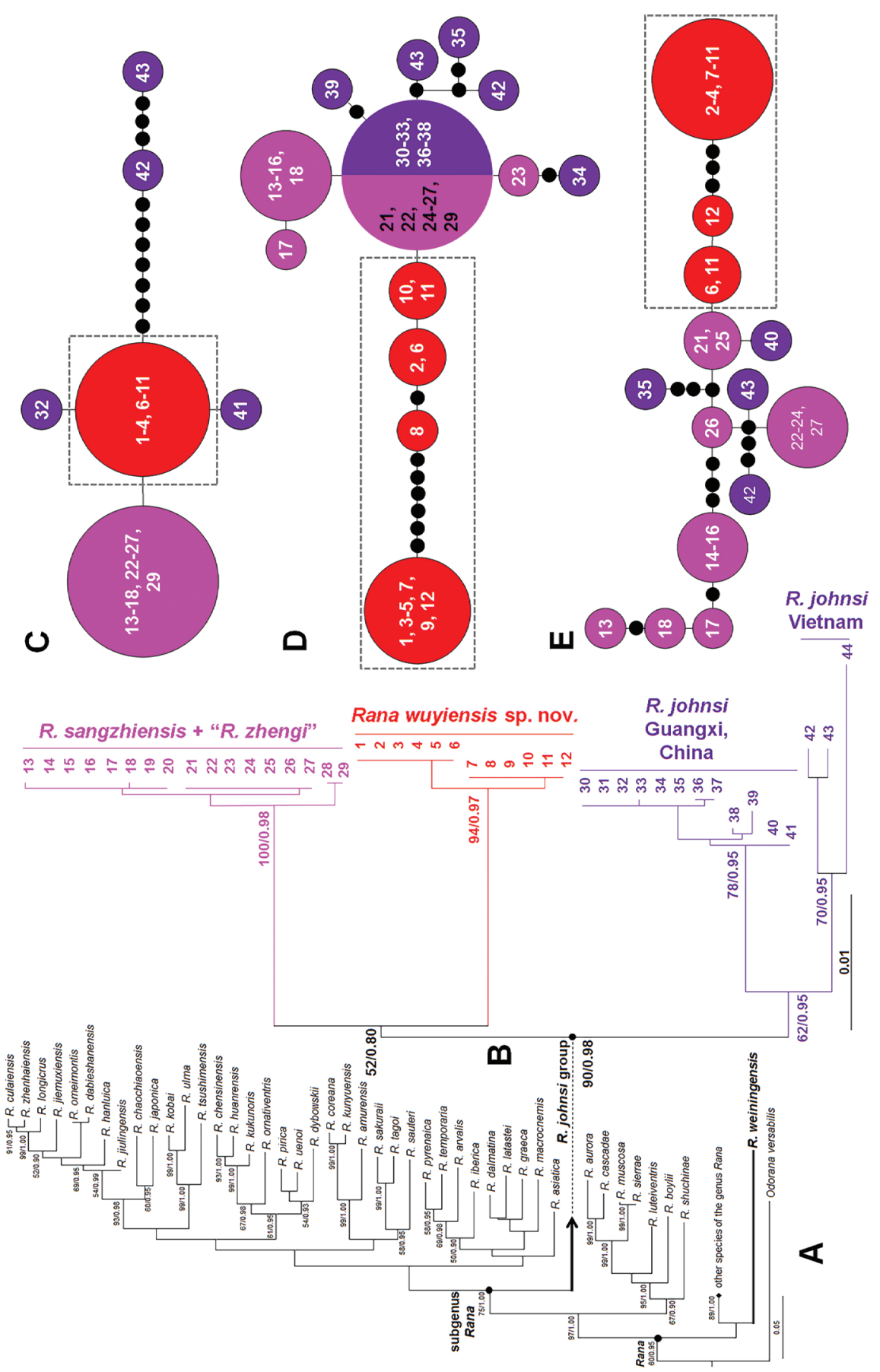

Figure 2. Phylogenetic relationships of Rana wuyiensis sp. nov. and its relatives $\mathbf{A}$ maximum likelihood (ML) tree reconstructed based on the 16S, ND2 and Cyt $b$ gene sequences $\mathbf{B}$ a part of the tree highlighting the relationships of the $R$. johnsi group. ML bootstrap supports/Bayesian posterior probability was denoted beside each node. Sample 1- 44 refer to Table 1 C-E haplotype networks constructed based on sequences of nuclear genes BDNF, RAG1, and Tyr, respectively. Different species of the $R$. johnsi group were denoted as different colors. 
species could be assigned to this species group by a series of morphological characters: tip of toes flat with lateroventral grooves; body size medium, SVL 41.4-45.6 mm (42.9 $\pm 1.9 \mathrm{~mm}, \mathrm{n}=4)$ in adult males and $47.6-50.3 \mathrm{~mm}(\mathrm{n}=2) \mathrm{mm}$ in adult females; dorsolateral fold distinct and thin, extending straight from posterior margin of upper eyelid to above groin; tympanum distinct, oval; tibio-tarsal articulation reaching forward beyond tip of snout when leg starched forward; skin ridges distinctly arranged on the dorsal surface of thighs and tibias; adult males with a pair of internal subgular vocal sacs; breeding males possess creamy white nuptial pad with tiny hoar velvety spines on the dorsal surface of the first finger, divided into three parts.

Although the $R$. johnsi group and $R$. weiningensis both have lateroventral grooves on the tip of toes, the undescribed species in the $R$. johnsi group could be easily distinguished from $R$. weiningensis by the following characters: males with internal subgular vocal sacs (vs. absent in the latter); males with lager body size $(41.4-45.6 \mathrm{~mm}, \mathrm{n}=4$ vs. $32.8-37.4 \mathrm{~mm}, \mathrm{n}=3$ in the latter); and more developed webbing between toes (webbing on fourth toes reaching tip of toe vs. reaching distal subarticular tubercle in the latter).

In the $R$. johnsi group, the undescribed species could be identified from its closely related species on morphology. ANOVA tests indicated that on the number of transverse skin ridges on the dorsal surface of thighs and tibias, the undescribed species significantly differs from its closely related species (all $p$-values $<0.01$; Table 3 ; Fig. 3 ). The undescribed species has larger number of transverse skin ridges either on thighs (mean $14.0 \pm 1.7$, range $12-16, \mathrm{n}=6$ ), on tibias (mean $12.5 \pm 2.0$, range $9-15, \mathrm{n}=6$ ), and totally on the two body parts (mean 26.5 \pm 2.7 , range 22-29, $\mathrm{n}=6$ ) than $R$. sangzhiensis (on thighs mean $9.7 \pm 1.3$, range $7-11, \mathrm{n}=7$; on tibias mean $10.1 \pm 1.1$, range $8-11, \mathrm{n}=7$; and totally on the two parts mean $19.9 \pm 1.8$, range $17-22, \mathrm{n}=7$ ), $R$. zhengi (on thighs mean $10.0 \pm 1.8$, range $7-15, \mathrm{n}=22$; on tibias mean $8.1 \pm 1.3$, range $6-12, \mathrm{n}=22$; and totally on the two parts mean $18.1 \pm 2.7$, range $15-22, \mathrm{n}=22$ ), $R$. johnsi from Vietnam (on thighs mean $9.3 \pm 2.3$, range $8-12, \mathrm{n}=3$; on tibias mean $9.0 \pm 1.0$, range $8-10, \mathrm{n}=3$; and totally on the two parts mean $18.3 \pm 3.2$, range $16-22, \mathrm{n}=3$ ), and $R$. johnsi from Guangxi, China (on thighs mean $10.3 \pm 0.9$, range 9-12, $\mathrm{n}=9$; on tibias mean $8.8 \pm 1.8$, range $6-12, \mathrm{n}=9$; and totally on the two parts mean $19.1 \pm 2.0$, range $16-22, \mathrm{n}=9$ ).

On morphometric characters, the results of One-way ANOVA showed that in male, the undescribed species was significantly different from $R$. sangzhiensis on SVL, HDL, SNT, IOD, UEW, ED, TYD, LAL, HAL, LW, THL, TL, TW, TFL, and FL (all $p$-values $<0.05$ ), significantly different from $R$. zhengi on HDL, HDW, SL, IND, IOD, UEW, TYD, LAL, LW, THL, TL, TW, and FL (all $p$-values $<0.05$ ), significantly different from $R$. johnsi from Vietnam on SVL, SNT, IND, ED, TYD, and LAL (all $p$-values $<0.05$ ), and significantly different from $R$. johnsi from Guangxi, China on HDL, HDW, SNT, IND, UEW, ED, LAL, LW, FIL, FIIIL, and TW (all p-values < 0.05; Table 4).

In total, molecular phylogenetic analyses and morphological comparisons indicated that our specimens from Wuyi Mountain, Fujian Province, China should be classified into the $R$. johnsi group, and are significantly divergent from its closely related species. The specimens should represent a new species which is described as following section. 

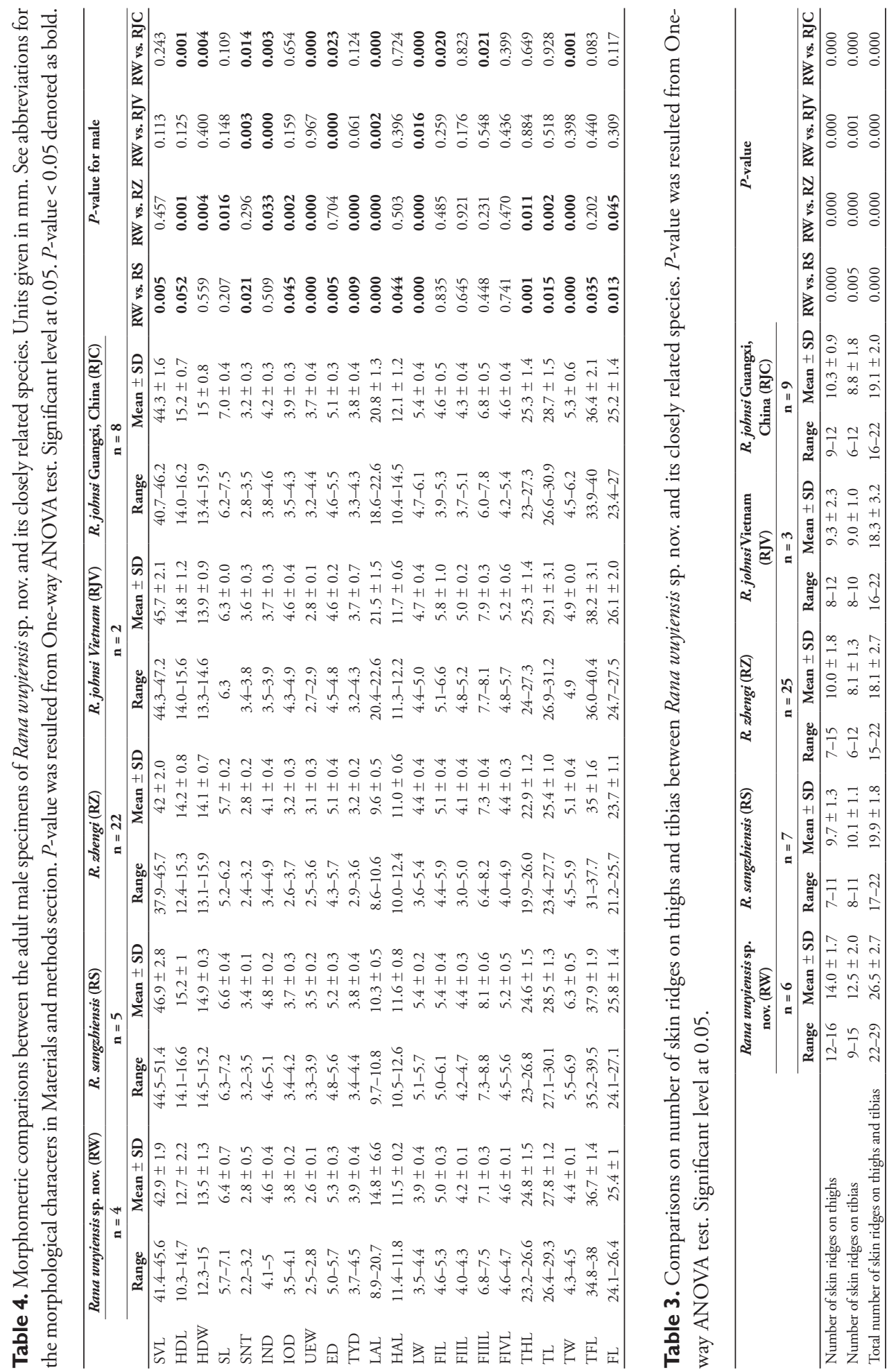


\section{Taxonomic account}

\section{Rana wuyiensis sp. nov.}

http://zoobank.org/66BA9380-4998-4EAF-9B58-7E0AEAB2C58C

Figs 3-6; Tables 1-4, Suppl. material 1

Material examined. Holotype (Figs 4, 5). CIB WY20200913003, adult male, collected by Yanqing Wu on 13 September 2020 from Wuyishan National Park $\left(27.760^{\circ} \mathrm{N}\right.$, $117.743^{\circ}$ E, ca. $1341 \mathrm{~m}$ a.s.l.), Wuyishan City, Fujiang Province, China. Paratypes. Five adult specimens from the same place as holotype collected by Yanqing Wu. One female CIB WYS20200829001 and two males CIB WYS20200829002 and CIB WY20200829003 were collected on 29 August 2020. One female CIB WY20200913002 and one male CIB WY20200913001 were collected on 13 September 2020.

Other material examined. Six tadpoles collected from the same place as holotype (Table 1) by Yanqing Wu on 01 November 2020.

Diagnosis. Rana wuyiensis sp. nov. is distinguished by a combination of the following morphological characters: body size medium, SVL 41.4-45.6 mm (42.9 \pm 1.9 $\mathrm{mm}, \mathrm{n}=4)$ in adult males, and $47.6-50.3 \mathrm{~mm}(\mathrm{n}=2)$ in adult females; lateroventral

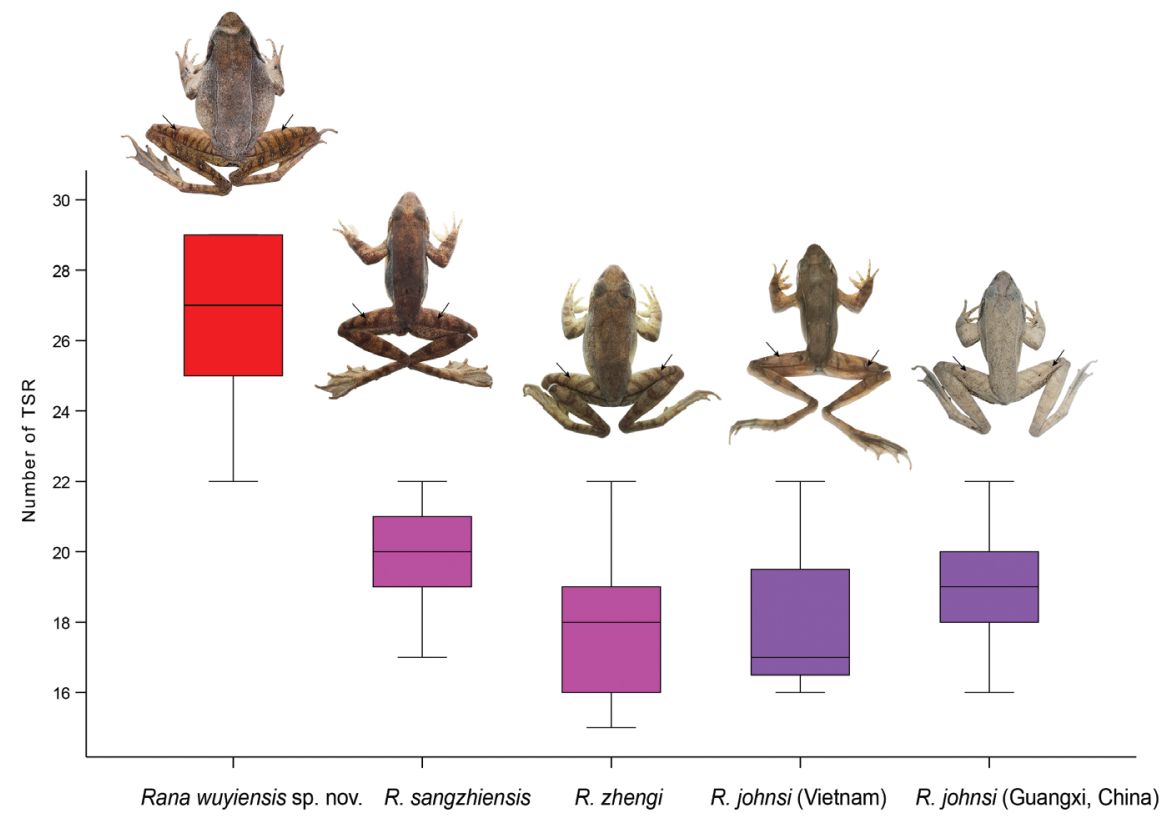

Figure 3. Box-plot showing the difference on the number of transverse skin ridges on the dorsal surface of thighs and tibias between different species. Specimens of different species: the holotype CIB WY20200913003 of Rana wuyiensis sp. nov., the topotype specimen CIB SZ2012061203 of $R$. sangzhiensis, the topotype specimen CIB 950300 of $R$. zhengi, the specimen NNU 1910009 of $R$. johnsi from Shiwandashan, Guangxi Province, China, and the specimen IEBR.A 4848 of $R$. johnsi from Vietnam. Abbreviation: TSR, transverse skin ridges. 

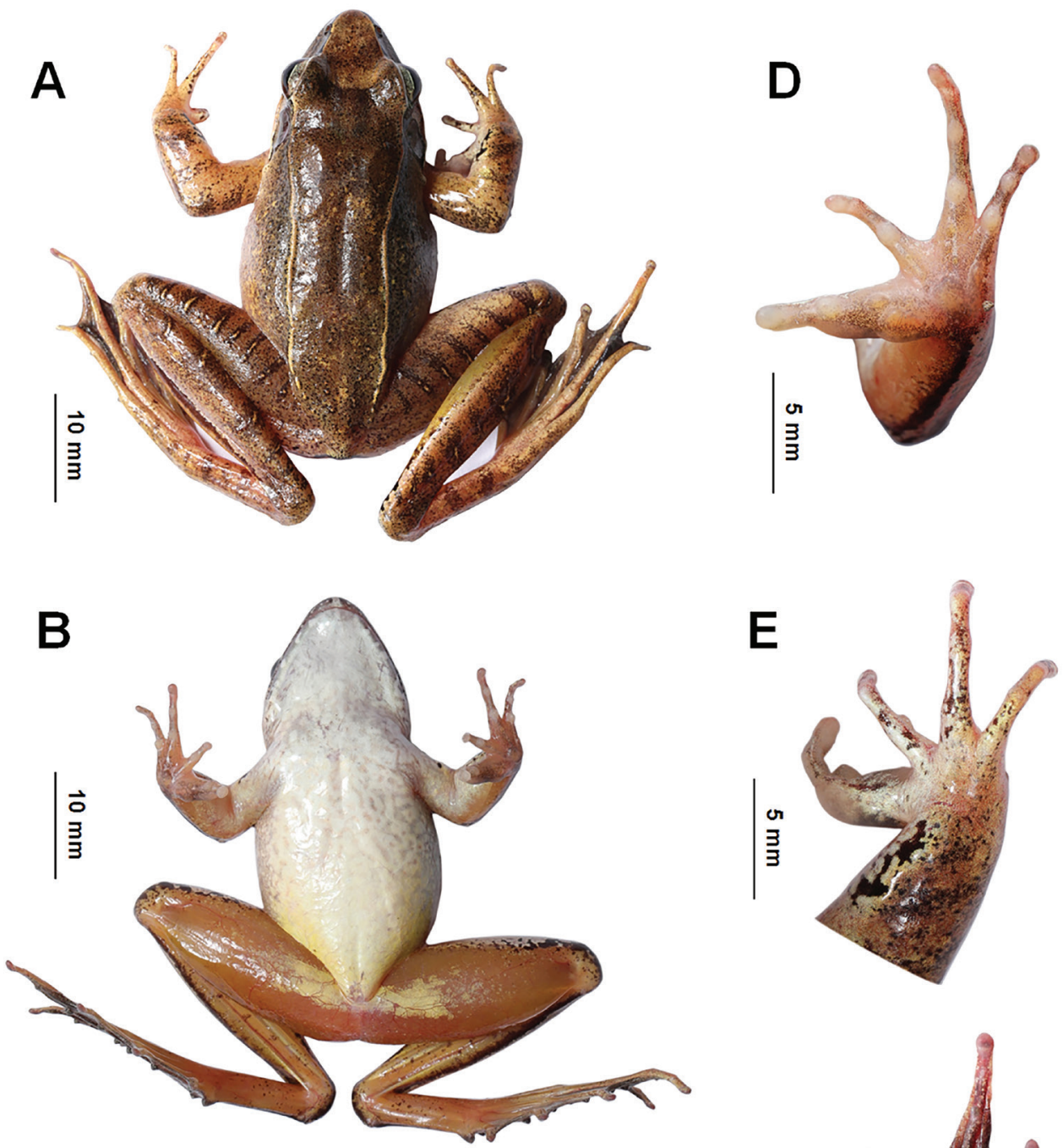

C
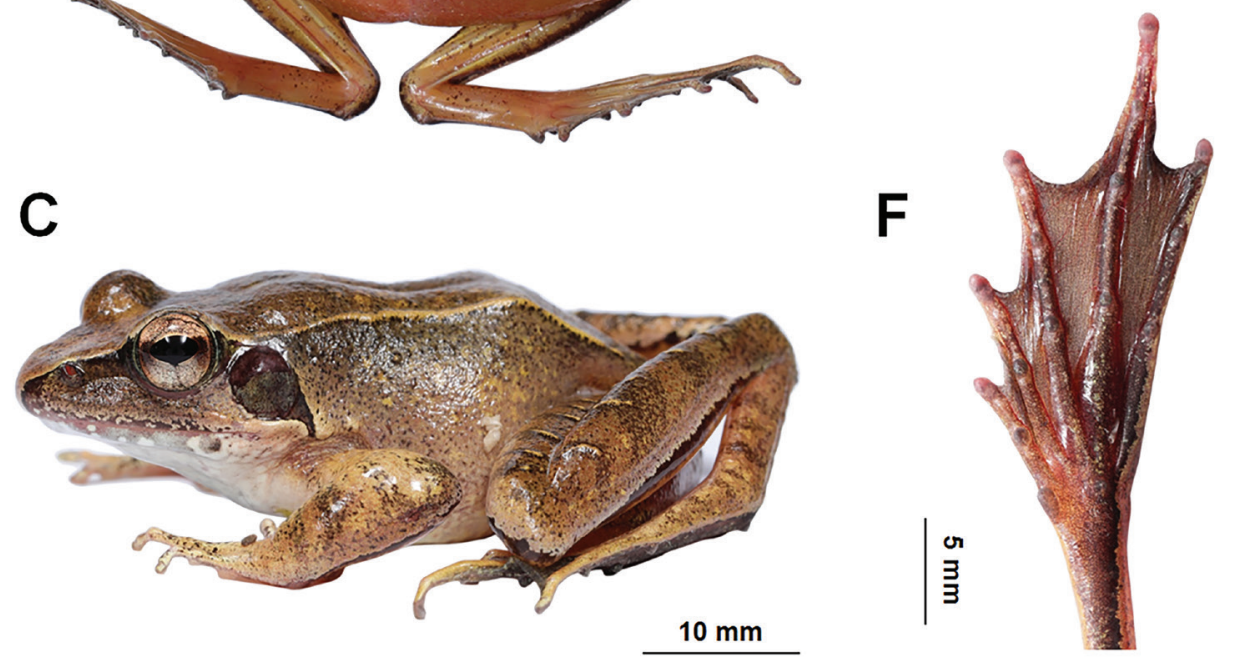

Figure 4. Photos of the holotype CIB WY20200913003 of Rana wuyiensis sp. nov. in life A dorsal view. $\mathbf{B}$ ventral view $\mathbf{C}$ lateral view $\mathbf{D}$ ventral view of hand $\mathbf{E}$ dorsal view of hand $\mathbf{F}$ ventral view of foot. 

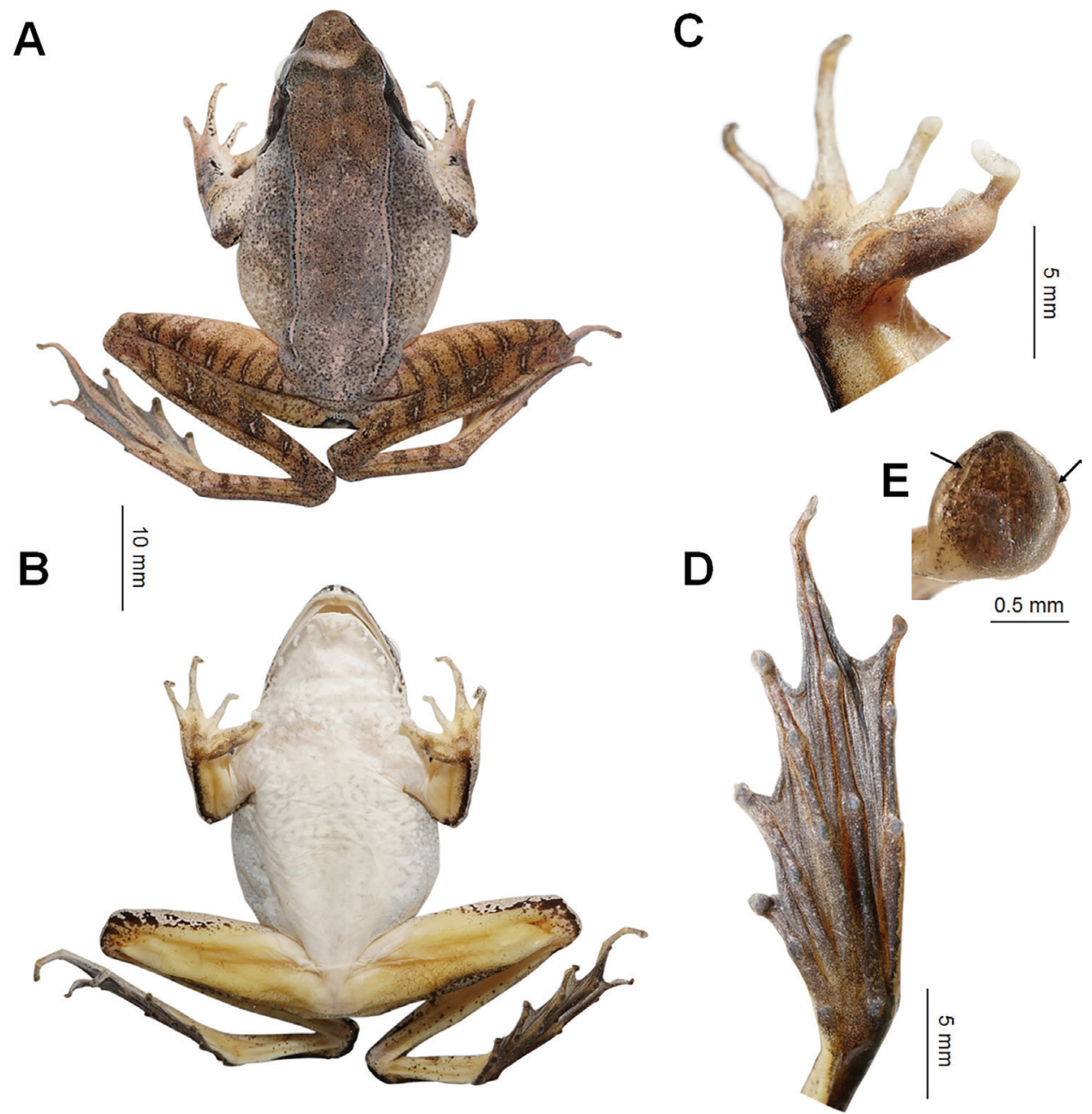

Figure 5. Photos of the holotype specimen CIB WY20200913003 of Rana wuyiensis sp. nov. A dorsal view $\mathbf{B}$ ventral view $\mathbf{C}$ ventral view of hand $\mathbf{D}$ ventral view of foot $\mathbf{E}$ ventral view of the toe highlighting the lateroventral grooves (arrows).

grooves present on tip of toes; transverse skin ridges distinctly present on the dorsal surface of thighs and tibias, the number large (mean 26.5 \pm 2.7 , range 22-29, $\mathrm{n}=6$ ); adult male with a pair of internal subgular vocal sacs; webbing on fourth toes reaching the tip of toe; breeding males possess creamy white nuptial pad with tiny hoar velvety spines on the dorsal surface of the first finger, divided into three parts.

Etymology. The specific name wuyiensis is in reference to the type locality, Wuyi Mountain, Fujian Province, China.

Suggested common name. Wuyi Brown Frog (in English), Wuyi Lin Wa (in Chinese; 武夷林蛙). 
Description of holotype (Figs 4, 5). Adult male; SVL $41.4 \mathrm{~mm}$. Head significantly longer than wide $(\mathrm{HDW} / \mathrm{HDL}$ ratio $=0.85)$; snout pointed and projecting over lower lip; nostril closer to tip of snout than eye; canthus rostralis distinct; internasal distance distinctly wider than interorbital distance $(\mathrm{IOD} / \mathrm{IND}$ ratio $=0.81)$; loreal region slightly oblique and concave; upper eyelids narrower than interorbital distance; tympanum rounded, diameter three quarters of eye $(\mathrm{TD} / \mathrm{ED}$ ratio $=0.75)$, and separated from eye by a short distance about one quarter of tympanum diameter; tympanic rim feebly elevated; pupil oval and horizontal, notched at middle lower margin; a skin fold present posterior to tympanum, disconnected with dorsolateral fold, swollen near shoulder; vomerine teeth in two short row, four or five for each, oblique and separated by a distance about one row of teeth; tongue deeply notched posteriorly, depth about one sixth of entire tongue length; a pair of internal subgular vocal sacs present, openings slit like, small, length as wide as finger tips, positioned at on inner mandible near the corners of mouth.

Forearms moderate, width 0.09 ratio of SVL; hand 0.27 ratio of SVL; fingers elongated, with narrow lateral fringes, rudimentary webbed, webbing formula I $32 / 3-22 / 3$ II $2^{1 / 2}-3^{1 / 2}$ III $3^{1 / 2}-3$ IV; tips of fingers rounded, not swollen, without lateroventral groove; finger II distinctly shorter than I, relative finger lengths II $<$ I $<$ IV $<$ III; subarticular tubercles prominent, rounded; supernumerary tubercles indistinct, oval, present on bases of all fingers; inner metacarpal tubercle distinct, near oval, positioned near inner surface of base of finger I, inner side partially covered with nuptial pad; two outer metacarpal tubercles partially separated near the joint of metacarpals of fingers III and IV, the inner oval and larger, the outer elongated and smaller; nuptial pad present on inner and dorsal surface of finger I, covered with velvety spines, partially divided into three parts, the basal part on inner side of inner metacarpal tubercle, the middle part largest, on third phalanx, the distal part smallest, on first and second phalanxes.

Hindlimbs long, tibia 0.64 ratio of SVL and length of foot and tarsus 0.84 ratio of SVL; thigh shorter than tibia, heels overlap when hindlimbs flexed at right angles to axis of body; tibio-tarsal articulation reaching far beyond snout when hindlimb stretched forward along body; toes entirely webbed, inner edge of toe I and outer edge of toe $\mathrm{V}$ with narrow lateral fringe, relative toe lengths I $<$ II $<$ III $<\mathrm{V}<\mathrm{IV}$, toes webbing formula: $1 \frac{1}{3}-2$ II $1 \frac{1}{3}-2^{1 / 3}$ III $1 \frac{1}{2}-2^{2} / 3$ IV $3-1 \frac{1}{3}$ V; tip of toes somewhat flat, lateroventral grooves present on all tip of toes and disconnected at middle of front edge; subarticular tubercles prominent and oval; supernumerary tubercles absent; inner metatarsal tubercle oval and prominent, outer metatarsal tubercle rounded, indistinct.

Dorsal skin smooth, supratympanic fold absent; dorsolateral folds distinct, narrow, extending from edge of upper eyelid to hip, not curve above tympanum. Ventral skin smooth, skins around cloaca with numerous flat tubercles. Skin on hindlimbs with transvers paralleled ridges, eight on both thighs, six and seven on left and right tibias, four and two on left and right tarsal. Tarsal fold present.

Coloration in life (Fig. 4). Dorsal surface basically medium brown, scattered with dense dark brown pigments all over; dorsolateral skin folds and skin ridges on dorsal 
A

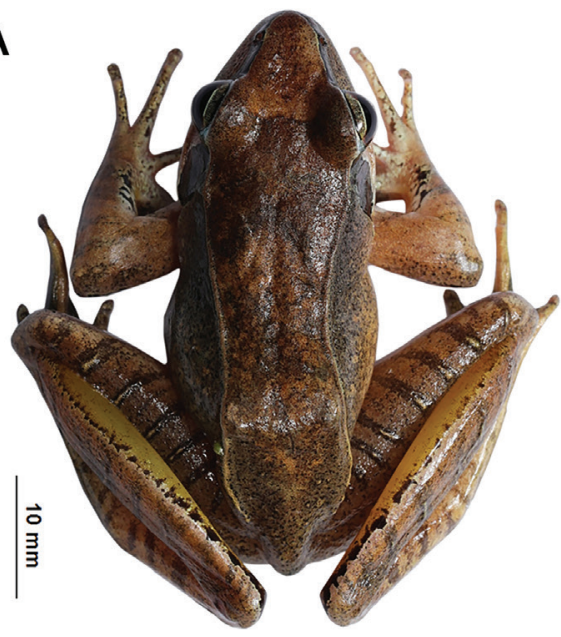

C

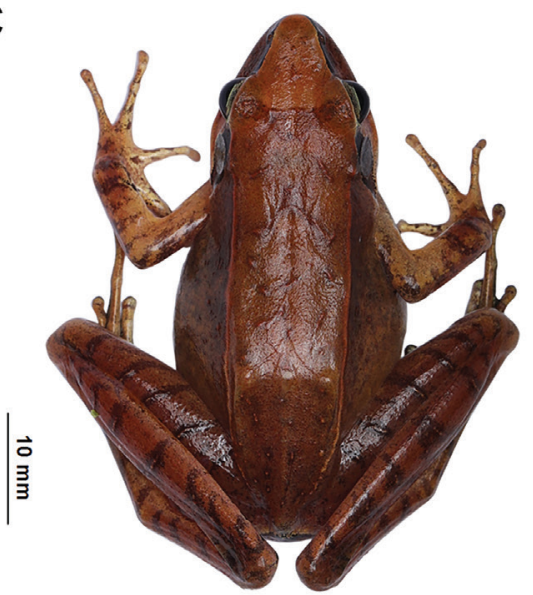

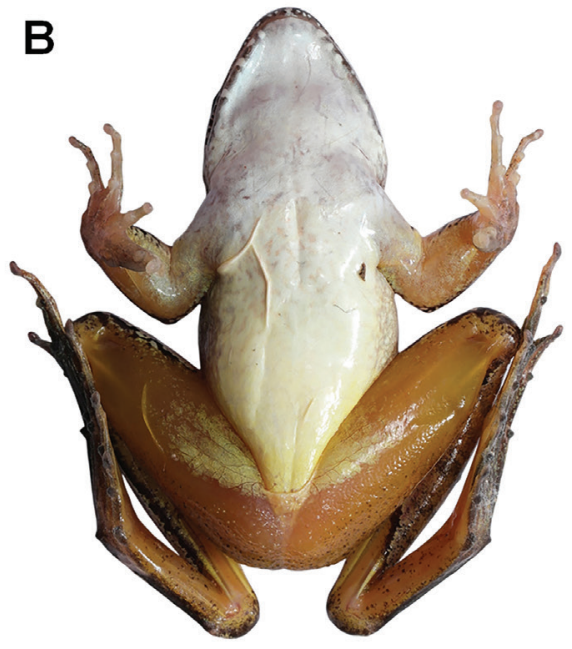

D

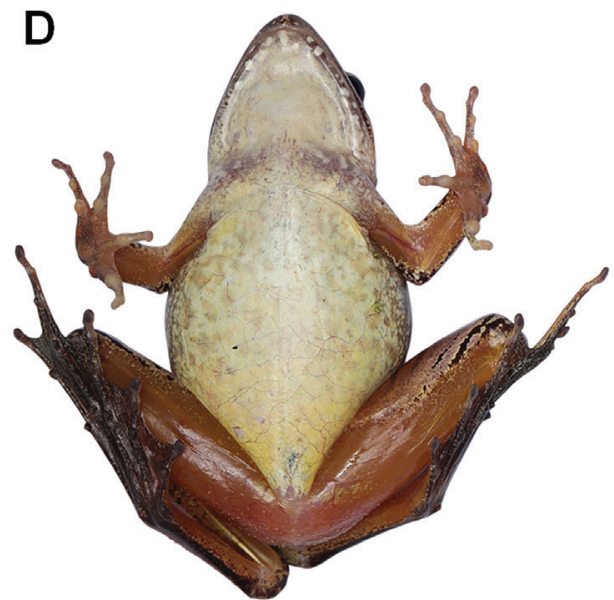

Figure 6. Color variation in Rana wuyiensis sp. nov. A dorsal view of the adult male specimen CIB WY20200913001 B ventral view of CIB WY20200913001 C dorsal view of the adult female CIB WY20200913002 D ventral view of CIB WY20200913002.

limbs yellow brown with deep drown fringes; five ambiguous deep brown cross bands present on dorsal forelimbs; irregular black patches present on inner surface of forearm near wrist, anterior knee and lateral tibia; lower edge of canthus rostralis dark brown; skins on tympanum and anterior to the fold behind tympanum deep brown; ventral skin basically cream white on body and arm; lips light brown with cream white patches; throat, chest, and upper abdomen with irregular light orangish short bars; ventral hindlimbs mostly flesh colored, with a small region near base of tinged yellowish white; ventral hand flesh-colored with brown pigments; ventral feet covered with dense brown pigments. Nuptial pad hoar. Iris mostly copper with dark cracks, regions anterior and posterior to pupil deeper. 
Coloration in preserve (Fig. 5). Body coloration lighter than in life, dark brown pigments more prominent. Skins between upper eyelids with an ambiguous brown pattern. Ventral body mostly white, with brown pattern; ventral limbs yellowish. Ventral hand and feet greyish. Skins on temporal region with prominent dark patches. Lateral head before eyes blackish. Iris dark with metal luster.

Secondary sexual characters. Breeding males with nuptial pad on dorsal surface of finger I, covered with velvety spines, divided into three parts. Male with a pair of internal subgular vocal sacs.

Variations. For measurements of type series specimens see Tables 4, Suppl. material 1. Coloration of the two females lighter (Fig. 6A), basically yellowish brown. Black edges of dorsolateral fold absent on CIB WY20200913002 (Fig. 6C) and indistinct on CIB WYS20200829001. The number of skin ridges on dorsal thigh range from five to eight. The skin ridges on tibia range from four to eight.

Distribution and ecology. Currently, Rana wuyiensis sp. nov. is known from Wuyishan National Park, Wuyishan City, Fujian Province, China. In our surveys from 2017 to 2021, the species was found only at one site. All individuals of the new species used in this work were collected from a stream and nearby grassland under the evergreen broad-leaf forest (Fig. 7). Six adult individuals and some very small tadpoles at early stages of development were found in the late August and early September. Only relative larger and middle-staged tadpoles were collected in the early November. This suggests that the breeding season of this species may begin in July or early August.

\section{Discussion}

Our results based on mitochondrial DNA and nuclear DNA of several populations of $R$. zhengi and $R$. sangzhiensis indicated that the two groups have very low genetic divergence. This is identical to the results of previous molecular phylogenetic analyses in Wan et al. (2020). In addition, we did not find morphological characters for separating the two groups, being consistent with the results of Jiang et al. (1997) and Fei et al. (2009). Based on this evidence, we support the proposal that $R$. zhengi should be synonymized with $R$. sangzhiensis. Accordingly, $R$. sangzhiensis is at least distributed from southwestern part of Sichuan to western Hunan provinces, China. On the contrary, Rana wuyiensis sp. nov. differs from its closely related species not only on morphology but also on molecular data, supporting the separation of the new species.

Moreover, the divergence between Rana wuyiensis sp. nov. and its closely related species in the $R$. johnsi group is likely corresponding to their separated distributional ranges (Fig. 1). Wuyi Mountain is located at the southeastern edge of the mainland China, far from the "west" distributional ranges of $R$. johnsi and $R$. sangzhiensis in southwestern China (at least $>400 \mathrm{~km}$ in a straight line between them; Fig. 1), and the distribution ranges belong to different biota (e.g., Zhang 2009; Fei et al. 2010). This indicates that vicariance might be the primary factor for the speciation of the species. Whatever, the discovery of the new species greatly expanded the distributional range of the $R$. johnsi group to the southeastern China and would promote exploring the biogeographical patterns in the frog group. 


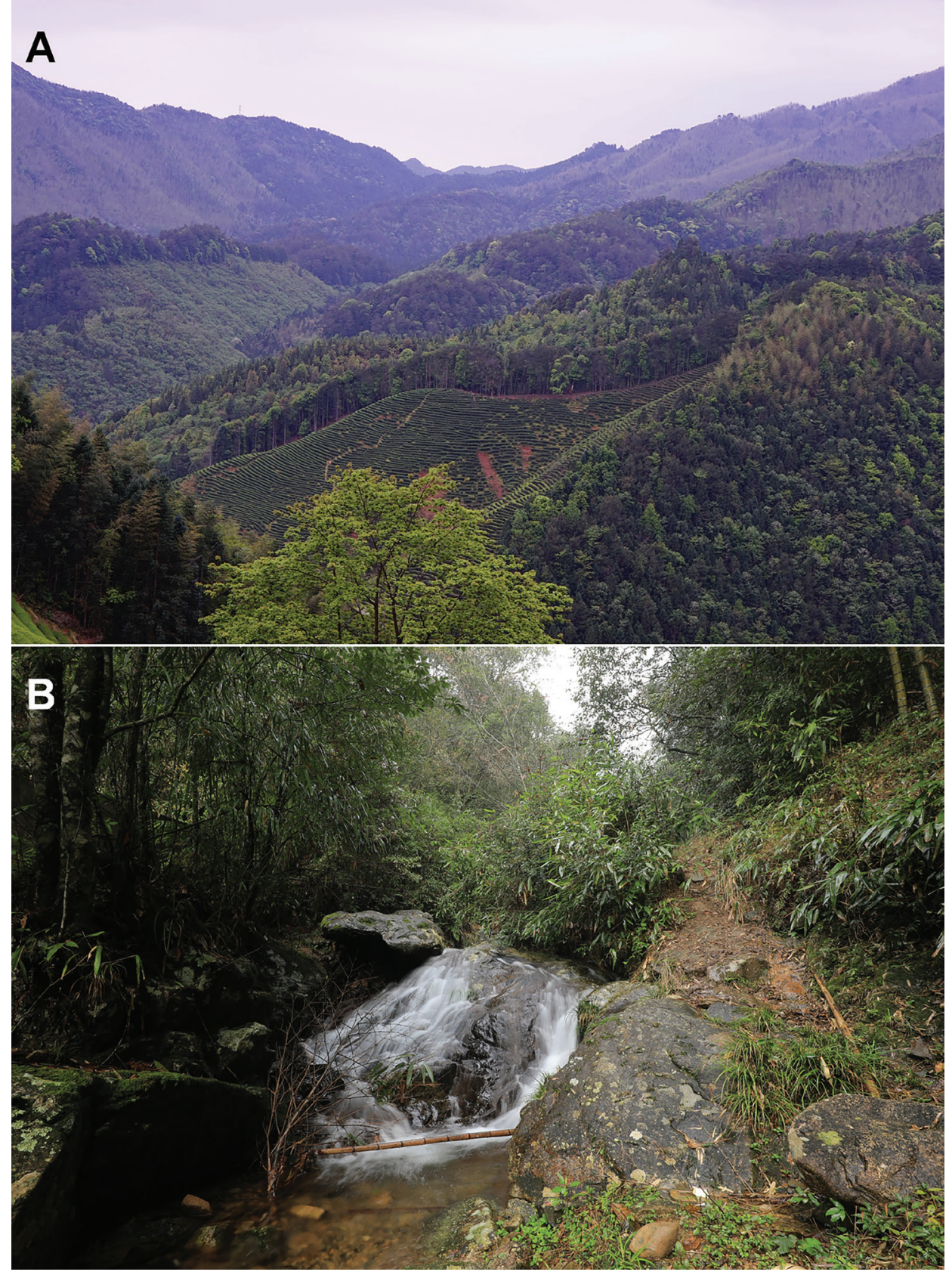

Figure 7. Habitats of Rana wuyiensis sp. nov. in the type locality, Wuyi Mountain, Fujian Province, China $\mathbf{A}$ landscape of montane forests in the type locality $\mathbf{B}$ a mountain stream in the type locality.

However, to date, Rana wuyiensis sp. nov. was found only at one site in Wuyi Mountain, and it probably has a low population size according to our eleven-times surveys which included forty sites every time in April, June, and August from 2018 to 2021. Although this site is in the central part of the Wuyishan National Park, the breeding 
habitat is vulnerable due to local human activities especially tea plantation (Fig. 7A) and/or local nature disaster (for example, the novel rainstorm in 2020 in Wuyi Mountain; our unpublished data). Therefore, we need to understand its population status and major threats, and then take appropriate actions to prepare strategies for its conservation.

\section{Acknowledgements}

We thank the editor and reviewers for their helpful suggestions on our work. This work was supported by Project of Biological Resources Survey in Wuyishan National Park. We thank Zhonghao Luo, Binqing Zhu, and Ningning Lu for their help with field work.

\section{References}

Batsch AJGK (1796) Umriß der gesammten Naturgeschichte: ein Auszug aus den frühern Handbüchern des Verfassers für seine Vorlesungen. Christian Ernst Gabler, Jena \& Leipzig, 287 pp.

Bedriaga JV (1898) Amphibien und Reptilien. Wissenschaftliche Resultate der von N. M. Przewalski nach Central-Asien unternommenen Reisen, \& c.-Nauchnuie Rezul'tatui puteshestvii N. M. Przheval'skagho po tzentral'noi Azii, \& c. Volume 3, Zoologischer Theil, Part 1. Akadamie der Wissenschaften, St. Petersburg, 71-278.

Boulenger GA (1886) Notes sur les grenouilles rousses d'Asie. Bulletin de la Société Zoologique de France 11: 595-600. https://doi.org/10.5962/bhl.part.24010

Boulenger GA (1909) Descriptions of four new frogs and a new snake discovered by Mr. H. Sauter in Formosa. Annals and Magazine of Natural History Series 8(4): 492-495. https:// doi.org/10.1080/00222930908692704

Che J, Pang JF, Zhao EM, Matsui M, Zhang YP (2007) Phylogenetic relationships of the Chinese Brown Frogs (genus Rana) inferred from partial mitochondrial 12S and 16S rRNA gene sequences. Zoological Science 24: 71-80. https://doi.org/10.2108/zsj.24.71

Clement M, Posada D, Crandall KA (2000) TCS: a computer program to estimate gene genealogies. Molecular Ecology 9(10): 1657-1659. https://doi.org/10.1046/j.1365-294x.2000.01020.x

David A (1875) Journal de mon Troisième Voyage d'Exploration dans l'Empire Chinoise. Vol. 1. Hachette, Paris, 383 pp. https://doi.org/10.5962/bhl.title.118647

Dubois A (1992) Notes sur la classification des Ranidae (Amphibiens anoures). Bulletin Mensuel de la Société Linnéenne de Lyon 61: 305-352. https://doi.org/10.3406/linly.1992.11011

Dubois A, Ohler A, Pyron RA (2021) New concepts and methods for phylogenetic taxonomy and nomenclature in zoology, exemplified by a new ranked cladonomy of recent amphibians (Lissamphibia). Megataxa 5: 1-738. https://doi.org/10.11646/megataxa.5.1.1

Fei L, Hu SQ, Ye CY, Huang YZ (2009) Fauna Sinica. Amphibia Vol. 2 Anura. Science Press, Beijing, 969-1121.

Fei L, Ye CY (2005) The key and illustration of Chinese. Sichuan Publishing House of Science and Technology. Chongqing, China, 102-116. 
Fei L, Ye CY, Huang YZ (1990) Key to Chinese Amphibians. Publishing House for Scientific and Technological Literature. Chongqing, China, 364 pp.

Fei L, Ye CY, Jiang JP (2010) Phylogenetic systematics of Ranidae. Herpetologica Sinica/Liang qi pa xing dong wu xue yan jiu 12: 1-43.

Fei L, Ye CY, Jiang JP (2012) Colored Atlas of Chinese Amphibians and their Distributions. Sichuan Publishing House of Science and Technology, Chengdu, 293-341.

Fitzinger LJFJ (1843) Systema Reptilium. Fasciculus Primus. Braumüller et Seidel, Wien, 106 pp. Frost DR (2021) Amphibian Species of the World: an Online Reference. Version 6.0. American Museum of Natural History, New York. http://research.amnh.org/herpetology/amphibia/ index.html [Accessed on: 2021-4-02]

Frost DR, Grant T, Faivovich J, Bain RH, Haas A, Haddad CFB, de Sá RO, Channing A, Wilkinson M, Donnellan SC, Raxworthy CJ, Campbell JA, Blotto BL, Moler PE, Drewes RC, Nussbaum RA, Lynch JD, Green DM, Wheeler WC (2006) The amphibian tree of life. Bulletin of the American Museum of Natural History 297: 1-370. https://doi. org/10.1206/0003-0090(2006)297[0001:TATOL]2.0.CO;2

Guindon S, Dufayard JF, Lefort V, Anisimova M, Hordijk W, Gascuel O (2010) New algorithms and methods to estimate maximum-likelihood phylogenies: assessing the performance of PhyML 3.0. Systematic Biology 59(3): 307-321. https://doi.org/10.1093/sysbio/syq010

Günther ACLG (1876) Description of a new frog from north-eastern Asia. Annals and Magazine of Natural History, Series 4, 17(101):387-387.https://doi.org/10.1080/00222937608681973

Hall TA (1999) BIOEDIT: a user-friendly biological sequence alignment editor and analysis program for Windows 95/98/NT. Nucleic Acids Symposium Series 41(41): 95-98.

Hallowell E (1861 “1860”) Report upon the Reptilia of the North Pacific Exploring Expedition, under command of Capt. John Rogers, U.S. N. Proceedings of the Academy of Natural Sciences of Philadelphia 12: 480-510.

Hu SQ, Fei L, Ye CY (1978) Three new amphibian species in China. Materials for Herpetological Research, Chengdu 4: 20.

Jiang JP, Fei L, Ye CY, Zeng XM, Zhen MQ, Xie F, Chen YY (1997) Studies on the taxonomics of species of Pseudorana and discussions of the phelogenetical relationships with its relative genera. Cultum Herpetologica Sinica/Liang qi pa xing dong wu xue yan jiu 6-7: 67-74.

Jiang JP, Xie F, Li C, Wang B (2020) Species Catalogue of China. Vol. 2. Animals, Vertebrates (IV), Amphibians. Science Press, Beijing, 129 pp.

LeConte JE (1825) Remarks on the American species of the genera Hyla and Rana. Annals of the Lyceum of Natural History of New York 1:278-282. https://doi.org/10.1111/j.1749-6632.1825. tb00012.x

Li PP, Lu YY, Li A (2008) A new species of brown frog from Bohai, China. Asiatic Herpetological Research 11: 62-70.

Linnaeus C (1758) Systema Naturae per Regna Tria Naturae, Secundum Classes, Ordines, Genera, Species, cum Characteribus, Differentiis, Synonymis, Locis. $10^{\text {th }}$ edn. Vol. 1. L. Salvii, Stockholm. https://doi.org/10.5962/bhl.title.37256

Liu CC (1946) A new woodfrog Rana chaochiaoensis with a discussion of its allied species, from West China. Journal of the West China Border Research Society, Series B 16: 7-14.

Liu CC (1950) Amphibians of western China. Fieldiana. Zoology Memoires 2: 1-397. [+ 10 pls.] https://doi.org/10.5962/bhl.part.4737 
Liu CC, Hu SQ (1962) A herpetological report of Kwangsi. Acta Zoologica Sinica/ Dong wu xue bao, Beijing 14(Supplement): 73-104.

Liu CC, Hu SQ, Yang FH (1962) Preliminary report of Amphibia from western Kweichow. Acta Zoologica Sinica/ Dong wu xue bao, Beijing 14: 381-392.

Liu MY, Zhang SQ, Liu M (1993) A new species of Ranidae from Liaoning, China (Anura). Acta Zootaxonomica Sinica 18: 493-497.

Lu YY, Li PP, Jiang DB (2007) A new species of Rana (Anura, Ranidae) from China. Acta Zootaxonomica Sinica/ Dong wu fen lei xue bao, Beijing 32: 792-801.

Nikolskii AM (1918) Fauna rossii i sopredel'nykh stran. Zemnovodnye. Russian Academy of Sciences, Petrograd, 284 pp.

Nilsson S (1842) Skandanavisk Herpetologi eller Beskrifning öfver de Sköldpaddor, Odlor, Ormar och Grodor, som Förekomma I Sverige Och Norrige, Hemte Deras Lefnadssätt, Födöamnen, Nytta och Skada MM. Gleerups, Lund, 347 pp. https://doi.org/10.5962/ bhl.title.43795

Ohler A (1995) Digital pad morphology in torrent-living Ranid frogs. Asiatic Herpetological Research 6: 85-96.

Okada Y (1928) Frogs in Korea. Chosen Natural History Society Journal/ Chosen Hakubutsu Gakkai zasshi 6: 15-46.

Pyron RA, Wiens JJ (2011) A large-scale phylogeny of Amphibia including over 2800 species, and a revised classification of advanced frogs, salamanders, and caecilians. Molecular Phylogenetics and Evolution 61: 543-583. https://doi.org/10.1016/j.ympev.2011.06.012

Ronquist F, Teslenko M, Van Der Mark P, Ayres DL, Darling A, Höhna S, Larget B, Liu L, Suchard MA, Huelsenbeck JP (2012) MrBayes 3.2: efficient Bayesian phylogenetic inference and model choice across a large model space. Systematic Biology 61: 539-542. https://doi.org/10.1093/sysbio/sys029

Sambrook J, Fritsch EF, Maniatis T (1989) Molecular cloning: a laboratory manual. Cold Spring Harbor Laboratory Press, New York, 1659 pp.

Savage JM (1975) Systematics and distribution of the Mexican and Central American stream frogs related to Eleutherodactylus rugulosus. Copeia 2: 254-306. https://doi.org/10.2307/1442883

Shen Y, Jiang J, Yang D (2007) A new species of the genus Rana-Rana hanluica sp. nov. from Hunan Province, China (Anura: Ranidae). Acta Zoologica Sinica 53: 481-488.

Shen YH (1986) A new ranid species (Rana sangzhiensis) from Hunan. Acta Herpetologica Sinica/ Liangqi baxing dongwu yanjiu, New Series, Chengdu 5(4): 290-294.

Smith MA (1921) New or little-known reptiles and batrachians from southern Annam (IndoChina). Proceedings of the Zoological Society of London 1921: 423-440. https://doi. org/10.1111/j.1096-3642.1921.tb03271.x

Stejneger L (1898) On a collection of batrachians and reptiles from Formosa \& adjacent islands. Journal of the College of Science, Imperial University, Japan 12: 215-225.

Tamura K, Stecher G, Peterson D, Filipski A, Kumar S (2013) MEGA6: molecular evolutionary genetics analysis, version 6.0. Molecular Biology and Evolution 30: 2725-2729. https://doi.org/10.1093/molbev/mst197

Wan H, Lyu ZT, Qi S, Zhao J, Li PP, Wang YY (2020) A new species of the Rana japonica group (Anura, Ranidae, Rana) from China, with a taxonomic proposal for the $R$. johnsi group. ZooKeys 942: 141-158. https://doi.org/10.3897/zookeys.942.46928 
Wang C, Qian L, Zhang C, Guo W, Pan T, Wu J, Wang H, Zhang B (2017) A new species of Rana from the Dabie Mountains in eastern China (Anura, Ranidae). ZooKeys 724: 135-153. https://doi.org/10.3897/zookeys.724.19383

Wang K, Ren JL, Chen HM, Lyu ZT, Guo XG, Jiang K, Chen JM, Li JT, Guo P, Wang YY, Che J (2020) The updated checklists of amphibians and reptiles of China. Biodiversity Science 28(2): 189-218. https://doi.org/10.17520/biods.2019238

Yan F, Jiang K, Chen H, Fang P, Jin J, Li Y, Wang S, Murphy RW, Che J, Zhang Y (2011) Matrilineal history of the Rana longicrus species group (Rana, Ranidae, Anura) and the description of a new species from Hunan, southern China. Asian Herpetological Research 2(2): 61-71. https://doi.org/10.3724/SP.J.1245.2011.00061

Yang BT, Zhou Y, Min MS, Matsui M, Dong BJ, Li PP, Fong JJ (2017) Diversity and phylogeography of Northeast Asian brown frogs allied to Rana dybowskii (Anura, Ranidae). Molecular Phylogenetics and Evolution 112: 148-157. https://doi.org/10.1016/j.ympev.2017.04.026

Ye CY, Fei L, Hu SQ (1993) Rare and economic amphibians of China. Sichuan Publishing House of Science and Technology, Chengdu, 412 pp.

Ye CY, Fei L, Matsui M (1995) Taxonomic studies of Chinese Rana japonica Guenther. Acta Herpetologica Sinica 4: 82-87.

Yuan ZY, Zhou WW, Chen X, Poyarkov Jr NA, Chen H-M, Jang-Liaw N-H, Chou WH, Matzke NJ, lizuka K, Min M-S, Kuzmin SL, Zhang YP, Cannatella DC, Hillis DM, Che J (2016) Spatiotemporal diversification of the true frogs (genus Rana): a historical framework for a widely studied group of model organisms. Systematic Biology 65: 824-842. https://doi.org/10.1093/sysbio/syw055

Zhao EM (1999) Diagnoses of a new frog and a new snake from China. Sichuan Journal of Zoology/Sichuan dong wu 18(3): 1.

Zhao HP, Yang JX, Wang CP, Li PP, Murphy RW, Che J, Yuan ZY (2017) A new species of the genus Rana from Henan, central China (Anura, Ranidae). ZooKeys 694: 95-108. https:// doi.org/10.3897/zookeys.694.12513

\section{Supplementary material I}

\section{Table $S 1$}

Authors: Bin Wang

Data type: morphological measurements of adults

Explanation note: Measurements of adult specimens of Rana wuyiensis sp. nov. and its closely related species. Units given in $\mathrm{mm}$. See abbreviations for the morphological characters in Materials and methods section.

Copyright notice: This dataset is made available under the Open Database License (http://opendatacommons.org/licenses/odbl/1.0/). The Open Database License $(\mathrm{ODbL})$ is a license agreement intended to allow users to freely share, modify, and use this Dataset while maintaining this same freedom for others, provided that the original source and author(s) are credited.

Link: https://doi.org/10.3897/zookeys.1065.67005.suppl1 